\title{
Hydroxyapatite-coated Collars Reduce Radiolucent Line Progression in Cemented Distal Femoral Bone Tumor Implants
}

\author{
Melanie J. Coathup BSc, PhD, Anish Sanghrajka MBBS, BS, \\ William J. Aston BSc, MBBS, Panagiotis D. Gikas MBBS, BSc, MD, PhD, \\ Robin C. Pollock MBBS, BSc, Stephen R. Cannon MA, MCh Orth, \\ John A. Skinner MBBS, Timothy W. R. Briggs MBBS, MChOrth, \\ Gordon W. Blunn BSc, PhD
}

Received: 3 July 2014/Accepted: 12 December 2014/Published online: 30 January 2015

(C) The Association of Bone and Joint Surgeons \& 2015

\begin{abstract}
Background Aseptic loosening of massive bone tumor implants is a major cause of prosthesis failure. Evidence suggests that an osteointegrated hydroxyapatite (HA)coated collar would reduce the incidence of aseptic loosening around the cemented intramedullary stem in distal femoral bone tumor prostheses. Because these implants often are used in young patients with a tumor, such treatment might extend the longevity of tumor implants. Questions/purposes We asked whether (1) HA-coated collars were more likely to osteointegrate; (2) HA collars
\end{abstract}

Each author certifies that he or she, or a member of his or her immediate family, has no funding or commercial associations (eg, consultancies, stock ownership, equity interest, patent/licensing arrangements, etc) that might pose a conflict of interest in connection with the submitted article.

All ICMJE Conflict of Interest Forms for authors and Clinical Orthopaedics and Related Research ${ }^{\mathbb{R}}$ editors and board members are on file with the publication and can be viewed on request.

Clinical Orthopaedics and Related Research ${ }^{\mathbb{R}}$ neither advocates nor endorses the use of any treatment, drug, or device. Readers are encouraged to always seek additional information, including FDA-approval status, of any drug or device prior to clinical use. Each author certifies that his or her institution approved or waived approval for the human protocol for this investigation and that all investigations were conducted in conformity with ethical principles of research.

This work was performed at the John Scales Centre for Biomedical Engineering, Institute of Orthopaedics, University College London, Royal National Orthopaedic Hospital, Stanmore, Middlesex, UK.

M. J. Coathup $(\bowtie)$, G. W. Blunn

John Scales Centre for Biomedical Engineering,

Institute of Orthopaedics and Musculoskeletal Science,

Division of Surgery and Interventional Science,

University College London,

London, UK

e-mail: m.coathup@ucl.ac.uk were associated with fewer progressive radiolucent lines around the stem-cement interface; and (3) HA-coated collars were associated with less bone loss at the boneshoulder implant junction?

Methods Twenty-two patients were pair-matched to one of two groups-either (1) implants with a HA-coated ingrowth collar (HA Collar Group); or (2) implants without an ingrowth collar (Noncollar Group). Age, sex, and length of followup were similar in both groups. HA-coated collars were developed and used at our institution from 1992 to address the high failure rate attributable to aseptic loosening in patients with massive bone tumor implants. Before this, smooth titanium shafts were used routinely adjacent to bone at the transection site. The minimum followup was 2 years (mean, 7 years; range, 2-12 years). Radiographs obtained throughout the followup period were analyzed and osteointegration at the shaft of the implant quantified. Radiolucent line progression around the cemented stem was semi-quantitatively assessed and cortical bone loss at the bone-shoulder implant junction was measured during the followup period.

Results Comparison of the most recent radiographs showed nine of 11 patients had osteointegrated HA collars, whereas only one patient in the Noncollar Group had osteointegration $(\mathrm{p}>0.001)$. The radiolucent line score quantified around the cemented stem was lower in the HA Collar Group when compared with the Noncollar Group $(p=0.001)$. Results showed an increase in cortical bone

M. J. Coathup, W. J. Aston, P. D. Gikas, R. C. Pollock, S. R. Cannon, J. A. Skinner, T. W. R. Briggs, G. W. Blunn The Royal National Orthopaedic Hospital, Brockley Hill, Stanmore, Middlesex HA7 4LP, UK

A. Sanghrajka

Norfolk and Norwich University Hospital, Norwich, UK 
loss at the bone-shoulder implant junction in the Noncollar Group when compared with the HA Collar Group $(\mathrm{p}<0.001)$.

Conclusions Osteointegration at the implant collar resulted in fewer radiolucent lines adjacent to the intramedullary cemented stem and decreased cortical bone loss immediately adjacent to the transection site. These results suggest that the HA collar may help reduce the risk of aseptic loosening in patients with this type of implant, but longer followup and a larger prospective comparison series are necessary to prove this more definitively.

\section{Introduction}

Insertion of a custom-made massive endoprosthesis that replaces a removed segment of bone is a well-established method of treating bone tumors of the distal femur [16, 21]. Aseptic loosening of distal femoral implants is a major cause of failure and Unwin et al. [28] reported a $67 \%$ probability of patients surviving aseptic loosening at 10 years. Other studies also have reported aseptic loosening as a major complication, with loosening rates of distal femoral prostheses between $3 \%$ and $29 \%$ at 4 to 10 years [1113, 16, 20, 27]. Current evidence suggests that patients with the poorest prognosis for survival are young, physically active patients who place high demands on their prostheses and in patients in whom a high percentage of the femur has been replaced [10, 28].

Aseptic loosening has been reported to initiate with localized cortical bone loss at the bone-shoulder implant junction where the bone is in direct contact with the shoulder of the implant [2, 3, 29, 30]. With time, osteolysis increases and cortical bone loss at the bone-shoulder implant junction is followed by the development and progression of periprosthetic bone-cement radiolucent lines that advance along the interface eventually leading to aseptic loosening of the component [2, 3, 29, 30]. Ward et al. [30] reported that loosening may be associated with wear debris-induced osteolysis. Concerns for successful long-term fixation stimulated modifications in implant design and extracortical bone-bridging and osteointegration at the bone-shoulder-implant junction, which may reduce aseptic loosening by producing a "purse string" that seals the bone interface, preventing migration of wear particles [30]. Aseptic loosening may be reduced by preserving load transfer at the shoulder of the implant through osteointegration leading to a reduction in stress in the cement mantle [5-7, 23, 26]. A telemetric study by Taylor et al. [26] showed that uncoupling of load from the shoulder of the implant toward the intramedullary stem tip occurred during a 23-month postoperative period in patients after massive bone tumor surgery. Blunn and Wait [3], in a histologic study, investigated bone growth adjacent to the intramedullary stem and reported bone remodeling consistent with the progressive transfer of load from the shoulder to the stem tip. Chao and Sim [6] used finite element analysis to show that extracortical bone-bridging with ingrowth to the implant shaft reduced stresses on the stem and in the cement mantle.

The aim of our study was to investigate and quantify extracortical bone growth and the development of radiolucent lines around the cemented interface in implants with and without a circumferential hydroxyapatite (HA)-coated ingrowth collar at the shoulder of distal femoral bone tumor implants. We asked whether (1) HA-coated collars were more likely to osteointegrate; (2) HA collars were associated with fewer progressive radiolucent lines around the stem during the followup period; and (3) HA-coated collars were associated with less bone loss at the boneshoulder implant junction?

\section{Materials and Methods}

Between 1990 and 2000, 84 primary limb salvage surgeries involving bone tumor resection and reconstruction using a cemented distal femoral endoprosthesis were performed at the Royal National Orthopaedic Hospital, Stanmore, UK. Thirty patients received a cemented distal femoral replacement with a smooth polished metal surface (Noncollar Group) and 54 received a cemented distal femoral replacement with a HA-coated grooved ingrowth collar located at the shoulder of the implant (HA Collar Group). HA-coated collars were developed and used at our institution from 1992 to address the high failure rate attributable to aseptic loosening in patients with massive bone tumor implants. Before this, smooth titanium shafts were used routinely adjacent to bone at the transection site.

Followup at a minimum of 2 years was available for $66 \%$ (20 of 30) of patients in the Noncollar Group and 39\% (21 of 54) of patients in the HA Collar Group. Patients with complete followup at a minimum of 2 years were considered eligible for pair matching as part of this study.

From these two groups, a total of 22 patients were pairmatched (11 matched pairs) and investigated in this study (Table 1). Fourteen patients were female, eight were male, and all were matched for age, length of bone resection, and length of followup because these factors have been established as independent risk factors for aseptic loosening of distal femoral endoprostheses [28]. The mean age of patients at the time of surgery was 36 years (range, 16-66 years). Patients were followed up at a minimum of 2 years (mean, 7 years; range, 2-12 years). The percentage of bone resected during surgery from each patient was calculated from AP radiographs and a mean of $37 \%$ 
Table 1. Data for the 22 pair-matched patients

\begin{tabular}{|c|c|c|c|c|c|c|c|}
\hline Match pair & Gender & $\begin{array}{l}\text { Age } \\
\text { (years) }\end{array}$ & Diagnosis & $\begin{array}{l}\text { Side } \\
\text { (right/left) }\end{array}$ & $\begin{array}{l}\text { Resection } \\
\text { length }(\%)\end{array}$ & $\begin{array}{l}\text { Maximum } \\
\text { followup (years) }\end{array}$ & $\begin{array}{l}\text { HA collar } \\
\text { (yes/no) }\end{array}$ \\
\hline \multirow[t]{2}{*}{1} & Female & 66 & Osteosarcoma & Right & 38 & 6 & No \\
\hline & Male & 63 & Osteosarcoma & Right & 41 & 2 & Yes \\
\hline \multirow[t]{2}{*}{2} & Female & 59 & Chondrosarcoma & Left & 29 & 10 & No \\
\hline & Female & 55 & Osteosarcoma & Left & 34 & 6 & Yes \\
\hline \multirow[t]{2}{*}{3} & Female & 50 & Osteosarcoma & Right & 42 & 10 & No \\
\hline & Male & 46 & Malignant fibrous histiocytoma & Right & 33 & 9 & Yes \\
\hline \multirow[t]{2}{*}{4} & Female & 26 & Malignant fibrous histiocytoma & Right & 47 & 6 & No \\
\hline & Male & 27 & Osteosarcoma & Left & 38 & 4 & Yes \\
\hline \multirow[t]{2}{*}{5} & Female & 30 & Osteosarcoma & Right & 34 & 7 & No \\
\hline & Female & 35 & Osteosarcoma & Right & 30 & 8 & Yes \\
\hline \multirow[t]{2}{*}{6} & Male & 32 & Osteoclastoma & Left & 25 & 11 & No \\
\hline & Female & 29 & Osteoclastoma & Left & 25 & 9 & Yes \\
\hline \multirow[t]{2}{*}{7} & Female & 16 & Osteosarcoma & Right & 43 & 9 & No \\
\hline & Female & 17 & Osteosarcoma & Left & 37 & 8 & Yes \\
\hline \multirow[t]{2}{*}{8} & Female & 17 & Osteosarcoma & Left & 38 & 5 & No \\
\hline & Male & 21 & Osteosarcoma & Right & 43 & 12 & Yes \\
\hline \multirow[t]{2}{*}{9} & Female & 24 & Osteoclastoma & Left & 31 & 10 & No \\
\hline & Female & 26 & Osteosarcoma & Right & 36 & 6 & Yes \\
\hline \multirow[t]{2}{*}{10} & Female & 21 & Osteosarcoma & Right & 44 & 3 & No \\
\hline & Male & 23 & Osteosarcoma & Left & 38 & 3 & Yes \\
\hline \multirow[t]{2}{*}{11} & Male & 62 & Chondrosarcoma & Left & 35 & 9 & No \\
\hline & Male & 60 & Malignant fibrous histiocytoma & Left & 33 & 6 & Yes \\
\hline
\end{tabular}

(range, 25\%-59\%) of the length of the femur was resected. When the groups were compared, the mean difference in age was 4 years (mean age: HA Collar Group, 37 years [range, 17-60 years]; Noncollar Group: 36 years [range, 16-66 years]). The difference in followup was 3 years (mean followup: HA Collar Group: 6.3 years [range, 3-12 years]; Noncollar Group: 8.1 years [range, 3-20 years]), and the mean difference in resection length between the two groups was 5\% (mean resection length: HA Collar Group: $35 \%$ [range, 25\%-43\%]; Noncollar Group: 34\% [range, 12\%$44 \%]$ ). No differences were found when the means of the groups were compared. All surgery was performed for primary bone tumors where osteosarcoma was the most common diagnosis $(64 \%)$, followed by malignant fibrous histiocytoma (14\%), giant cell tumor (14\%), and chondrosarcoma $(9 \%)$. None of the implants was revised during the investigative period and each patient received a unilateral implant with 11 inserted in the right leg and 11 in the left.

All prostheses were designed by Stanmore Implants Ltd (Elstree, Hertfordshire, UK) and manufactured on a customized case-by-case basis. The shaft and intramedullary stem were made from titanium alloy $\left(\mathrm{Ti}_{6} \mathrm{Al}_{4} \mathrm{~V}\right)$ and when indicated, the stem was shaped to follow the natural curvature of the bone. After resection of the knee, all patients in this study received the SMILES ${ }^{\mathrm{TM}}$ rotating hinge total joint (Stanmore
Implants Ltd) made from cast cobalt-chrome-molybdenum alloy. The tibial and femoral intramedullary stems were cemented in place. The HA collar was composed of circumferential and longitudinal grooves manufactured $1.5 \mathrm{~mm}$ deep, $1 \mathrm{~mm}$ apart, and $1 \mathrm{~mm}$ wide. A highly crystalline plasma-sprayed HA coating ( $>85 \%$ crystallinity and $50 \mu \mathrm{m}$ thick; Plasma Biotal, Derby, UK) was applied to each collar before surgery. In the Noncollar Group, the shaft at the shoulder of the implant had a smooth, polished surface finish.

Where appropriate, patients received neoadjuvant chemotherapy and all met the criteria for limb salvage [24]. Patients were given chemotherapy after surgery and partial weightbearing was allowed during the first 6 weeks after surgery, slowly progressing to full weightbearing. After 6 weeks, patients returned for a period of intensive physiotherapy. All procedures were performed at one institution and no patients were recalled specifically for this study; all data were obtained from the medical records and postoperative radiographs.

\section{Radiographic Analysis}

Radiographic analysis was performed by one observer (AS) and measurements ( $\mathrm{mm} \pm$ standard deviation [SD]) were 
Table 2. Radiographs assessed in the HA Collar $(n=102)$ and Noncollar $(n=100)$ Groups

\begin{tabular}{|c|c|c|c|c|c|c|c|c|c|}
\hline \multirow[t]{2}{*}{ Group } & \multicolumn{9}{|c|}{ Followup } \\
\hline & 1 year & 2 years & 3 years & 4 years & 5 years & 6 years & 7 years & 8 years & 9 years \\
\hline HA Collar Group & 30 & 16 & 13 & 13 & 8 & 9 & 6 & 5 & 2 \\
\hline Noncollar Group & 21 & 13 & 11 & 10 & 13 & 9 & 10 & 7 & 6 \\
\hline
\end{tabular}

made from the AP and mediolateral radiographs taken of each patient beginning immediately postoperatively and at intervals throughout their followup. On average, patients attended outpatient clinic three times a year and radiographs were taken on each occasion. The number of radiographs analyzed for each patient varied according to length of followup; however, a mean of 10 (range, 5-16) radiographs were analyzed per patient in this study. In total, 102 radiographs were measured in the HA Collar Group and 100 in the Noncollar Group during the followup period (Table 2).

Each of the radiographs was used to quantify: (1) the presence of radiolucent lines between extracortical bone and the implant collar; (2) the presence and progression of radiolucent lines around the cemented intramedullary stem fixation and; (3) the extent of cortical bone loss immediately beneath the implant shaft at the shoulder of the prosthesis.

\section{Radiolucent Line Measurements Between Extracortical}

Bone and the Implant Collar

Before analysis, radiographs were calibrated by measuring the known length of the femoral intramedullary stem on the radiograph, thereby producing a magnification factor. Radiolucent lines that separated extracortical bone growth at the collar surface were quantified by measuring their mean maximal thickness. Each collar region was first divided into four quadrants and the presence of a radiolucent line was quantified in the medial, lateral, anterior, and posterior views. Where radiolucent lines were present and where there was no evidence of osteointegration at the collar, the implant was considered not ingrown (Fig. 1).

\section{Radiolucent Line Score: Cemented Intramedullary}

Fixation

Progressive radiolucent lines at the cement-bone interface adjacent to the intramedullary stem were quantified from serial routine $\mathrm{AP}$ and mediolateral radiographs taken throughout the followup period. The medial, lateral, anterior, and posterior aspects adjacent to the intramedullary stem were each divided into six equidistant zones (Fig. 2).
When a radiolucent line was observed at the cement-bone interface in a zone, a score of 1 was given. Therefore, a maximal score of 12 could be obtained from each radiograph and a total score of 24 would indicate a prosthesis that was surrounded by radiolucent lines along the entire stem on AP and mediolateral radiographs. A score of 0 indicated that no radiolucent lines were measured. Radiolucent lines around the cement stem were measured on radiographs and the progression of these lines was determined by their increase in length with time.

Cortical Bone Loss at the Bone-shoulder Implant Junction

The distance that separated bone from the shoulder of the implant located directly above the transection site was measured and quantified during the followup period for each of the 22 patients (Fig. 3).

\section{Statistics}

Using data obtained from the most recent AP and mediolateral radiographs, the Mann-Whitney U test was used for statistical comparison between the HA Collar and Noncollar Groups where $\mathrm{p}$ values less than 0.05 were considered significant (Version 10.1; SPSS, Chicago, IL, USA). Radiolucent line score and cortical bone loss when measured throughout the followup period were univariately assessed for association with osteointegration at the collar using the Spearman rank coefficient. Mean values \pm SD are presented.

\section{Results}

Extracortical Bone Formation and Osteointegration of the Collar

With the numbers available, there were no differences between the collared and noncollared stems in terms of extracortical bone formation. In the HA Collar Group, 10 of 11 patients had extracortical bone growth in at least one of the four quadrants adjacent to the collar. In the 


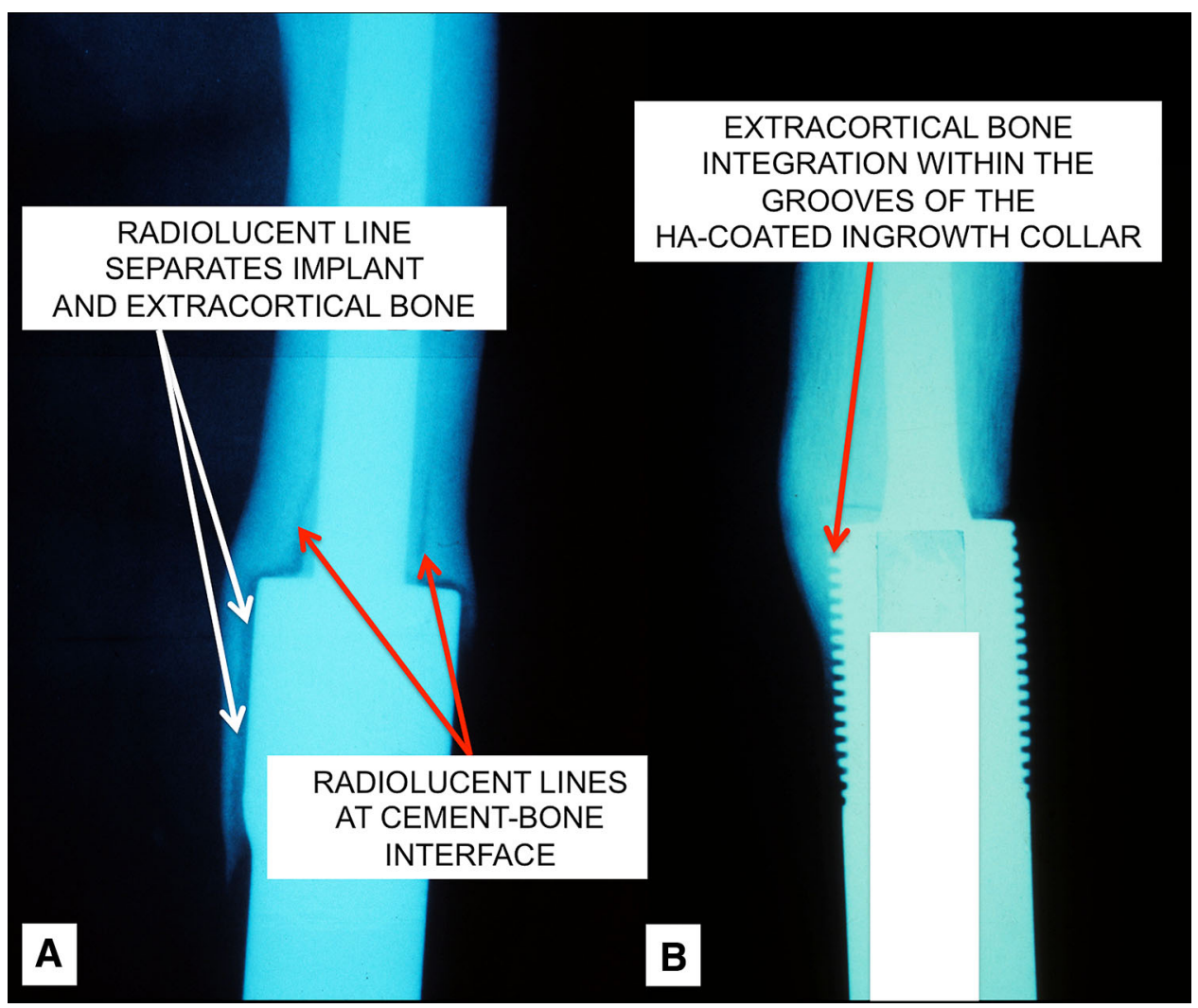

Fig. 1A-B (A) An AP radiograph of a noncollared implant obtained 3 years after surgery shows a clear radiolucent margin separating the newly formed extracortical bone growth with the implant surface (white arrows). This collar was considered not ingrown. The red arrows indicate the radiolucent lines that are present at the cement-

Noncollar Group, nine of 11 patients showed bone growth in at least one region. Osteointegration was more consistent in the stems with HA collars. Nine of the 11 patients in that group had direct bony ingrowth (as defined by the absence of a radiolucent line) in at least one of the four regions measured. In the Noncollar Group, results showed that only one patient had direct radiologic contact in one region of the implant surface (Fig. 4). Overall, thicker radiolucent lines were measured adjacent to the implant shaft in the Noncollar Group (mean, $2 \pm 1.65 \mathrm{~mm}$ ) compared with the HA Collar Group (mean, $0.15 \pm 0.46 \mathrm{~mm})(\mathrm{p}<0.001)$ (Fig. 5).

\section{Radiolucent Line Score: Intramedullary Stem Fixation}

Results showed a lower radiolucent line score adjacent to the cemented intramedullary stem in implants with a grooved HA-coated collar (mean, $0.58 \pm 1.66$; range, $0-7$ ) when compared with implants in the Noncollar Group (mean, $4 \pm 5.31$; range, $0-18)(\mathrm{p}=0.002)$ (Fig. 6). Results showed that in the HA Collar Group and throughout the bone interface in the stem fixation. (B) An AP radiograph of the pairmatched HA-coated collared implant obtained 1 year after surgery shows bone integration in the grooves with direct contact with the implant surface (white arrows). This collar was considered ingrown.

followup period, the score for each of the 11 patients did not increase greater than seven. In the Noncollar Group radiolucent lines were seen to gradually increase with time. In the Noncollar Group and when the radiolucent line score was compared with time, a higher radiolucent line score was measured in each of the yearly increments when compared with 1 year postoperatively (except 2 years) ( $\mathrm{p}<0.001$ in all cases). The radiolucent line scores measured at 10 and 11 years were higher when compared with at all other times ( $\mathrm{p}<0.001$ in all cases). No substantial differences in radiolucent line scores between any of the yearly times were found in the HA Collar Group.

Cortical Bone Loss at the Bone-Shoulder Implant Junction

Results showed that more cortical bone loss at the boneshoulder implant junction occurred in the Noncollar Group (mean, $1.07 \pm 1.47 \mathrm{~mm}$; range, $0-9 \mathrm{~mm}$ ) when compared with implants in the HA Collar Group (mean, $0.39 \pm 0.61$; range, $0-2 \mathrm{~mm})(\mathrm{p}<0.001)$. Cortical loss remained 


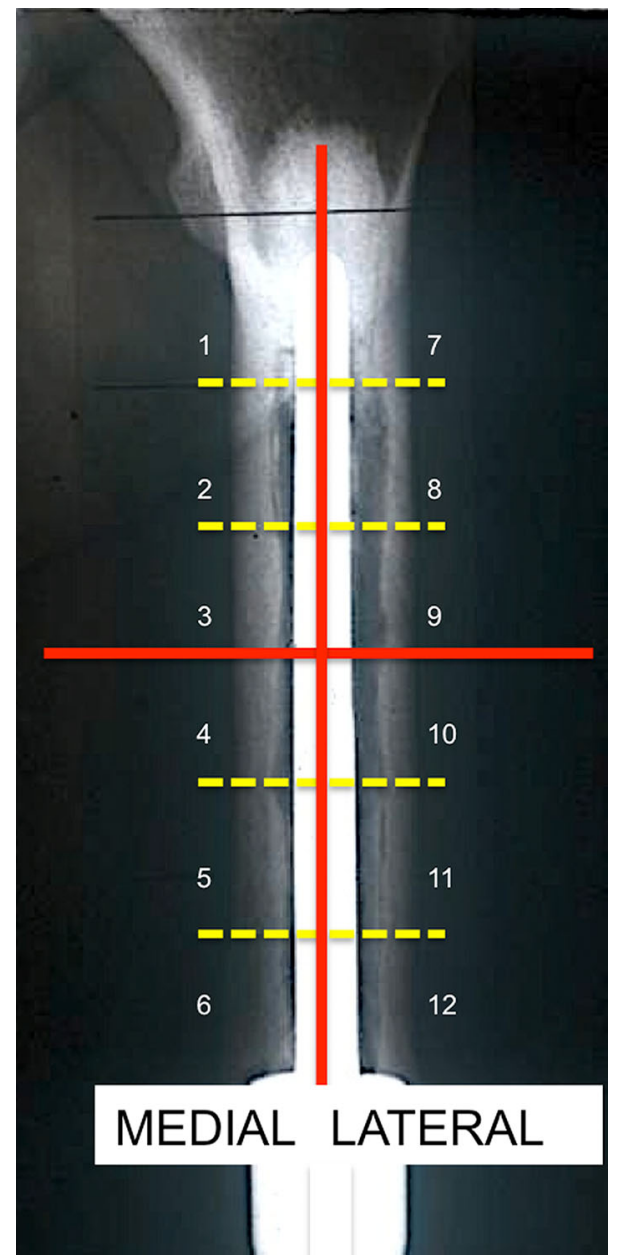

Fig. 2 An AP radiograph shows the dividing lines that created six zones along the medial and lateral intramedullary stem length, respectively. A maximal score of 12 would indicate the presence of a radiolucent line in all 12 of the divided zones. Twelve zones also were assessed on mediolateral radiographs.

constant during the followup period in the HA Collar Group (Fig. 7) but appeared to gradually increase with time in the Noncollar Group; however, no substantial correlation was found.

Correlation of Extracortical Bone and Radiolucent Lines

In the Noncollar Group where there was extracortical bone formation, radiolucent line thickness adjacent to the extracortical bone increased with time $(\mathrm{p}<0.001)$. However, no correlations were found with radiolucent lines adjacent to the HA collar. Compared with the postoperative radiograph, radiolucent lines at the stem-cement interface were more prevalent on the last available radiograph. With time there was progression of radiolucent lines along the stem-cement interface in the Noncollar Group $(p=0.071)$;

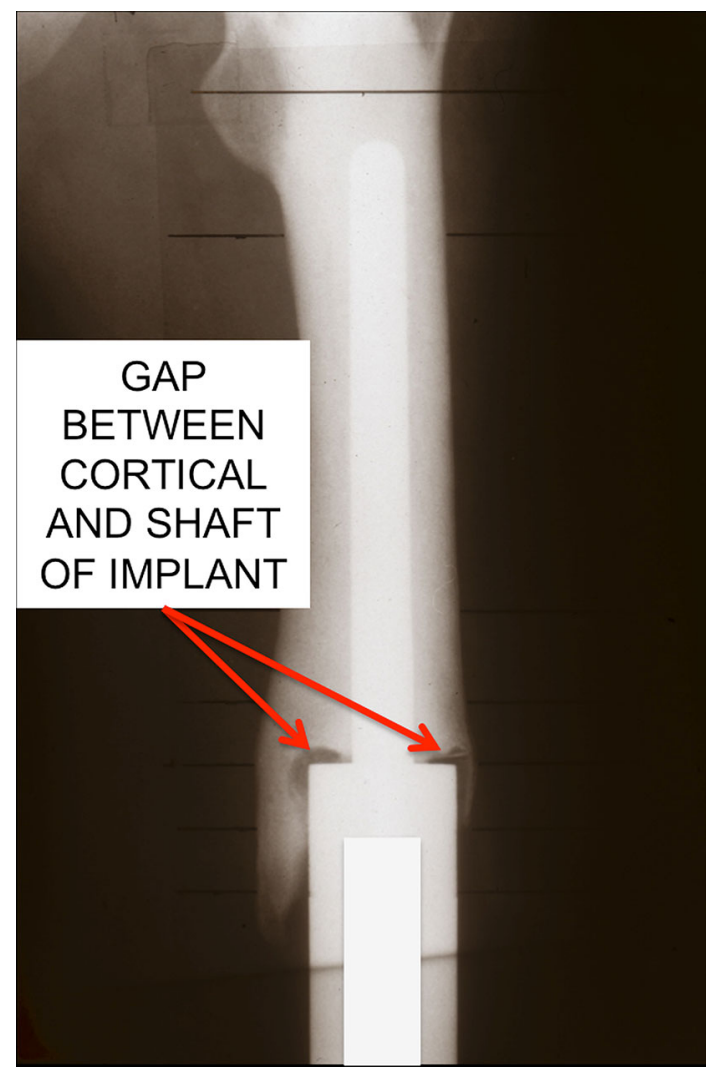

Fig. 3 A mediolateral radiograph of an implant in the Noncollar Group at 1 year postsurgery shows cortical loss adjacent to the implant shoulder.

however, in the HA Collar Group there was no difference in the radiolucent line score when the postoperative radiograph was compared with the last available radiograph $(\mathrm{p}=0.745)$.

\section{Discussion}

Aseptic loosening of the intramedullary stem is one of the major causes of distal femoral prosthesis failure. The only identifiable risk factors reported in the literature are age, bone resection length, and time of followup [28]. In theory, osteointegration of extracortical bone growth to the shaft of the implant may be associated with a more advantageous biomechanical environment and improved stem fixation [5-7, 23, 26]. This also may be associated with formation of a "purse string", which prevents wear particles from migrating between the stem-bone interface causing osteolysis [30]. In this study, we evaluated the effect of hydroxyapatite coating of the implant and found that a hydroxyapatite coating reduced the incidence of progressive radiolucent lines around the stem of the implant.

Our study had limitations. First, it was a retrospective analysis where variation was minimized by pair-matching 


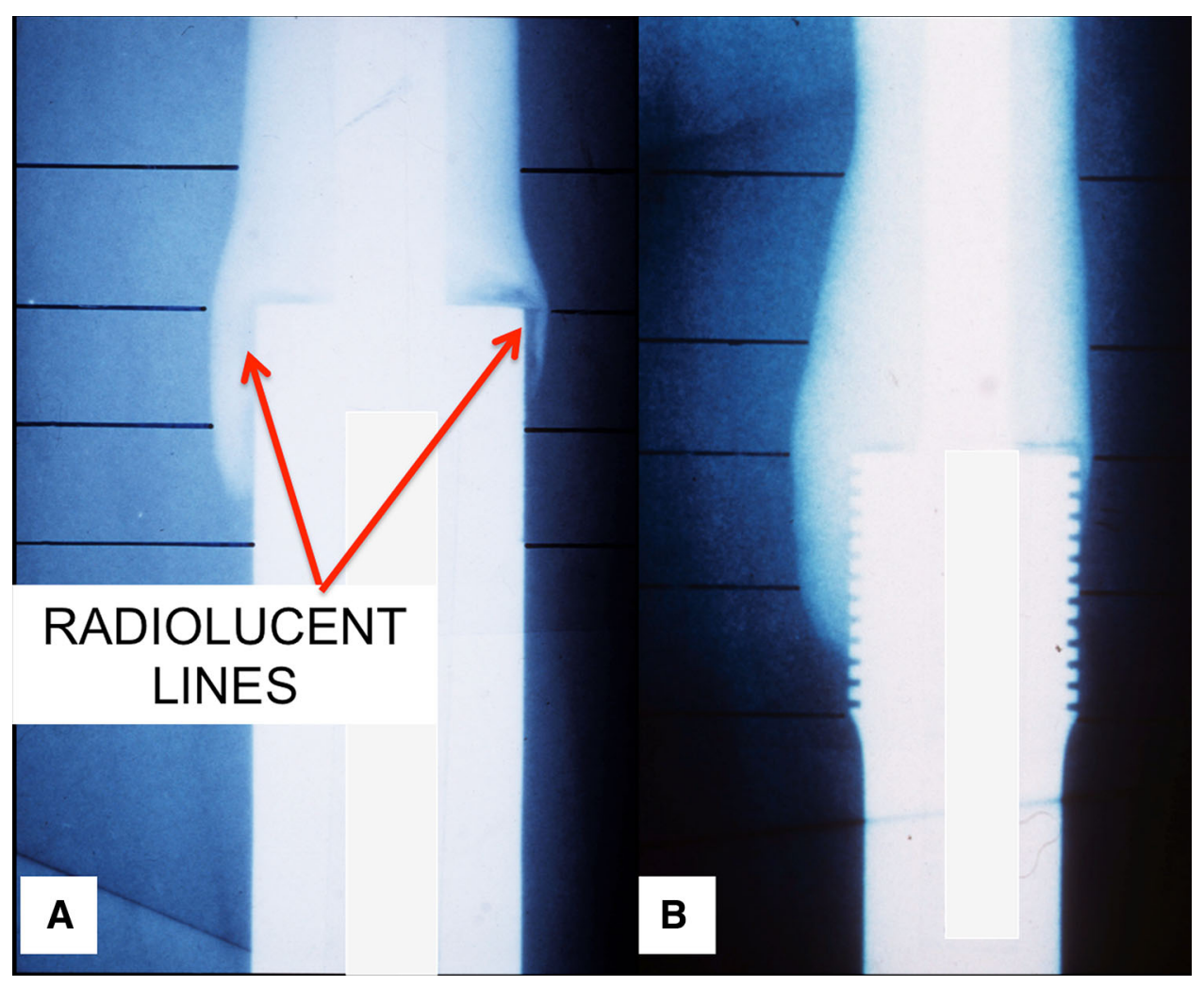

Fig. 4A-B (A) An AP microradiograph from a patient in the Noncollar Group at 4-year followup shows radiolucent lines separating the implant surface and bony pedicle. (B) An AP microradiograph

from a pair-matched patient in the HA Collar Group at 1-year followup shows osteointegration of the collar.

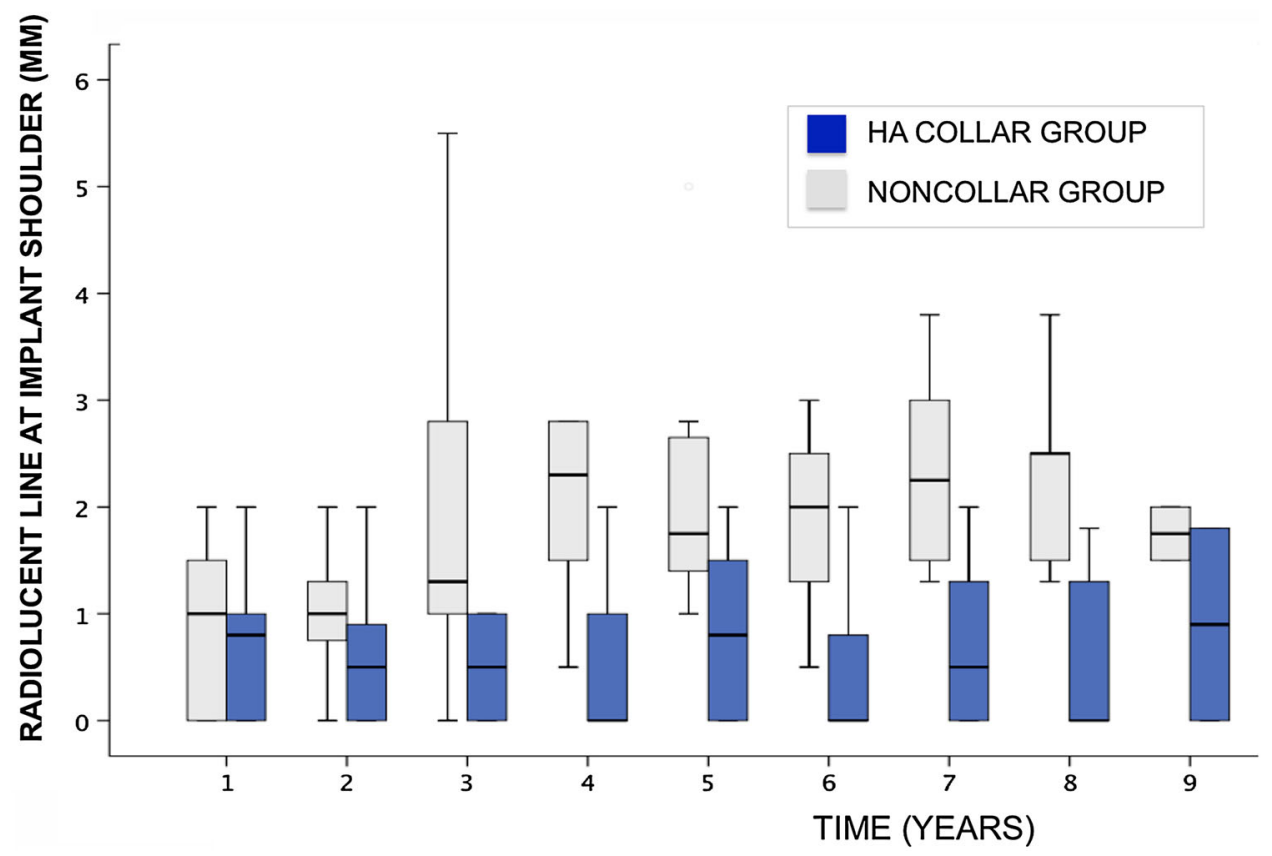

Fig. 5 The thicknesses $(\mathrm{mm})$ of the radiolucent lines measured between the extracortical bone pedicle and implant shaft in the HA Collar and Noncollar Groups during the study period are shown. 


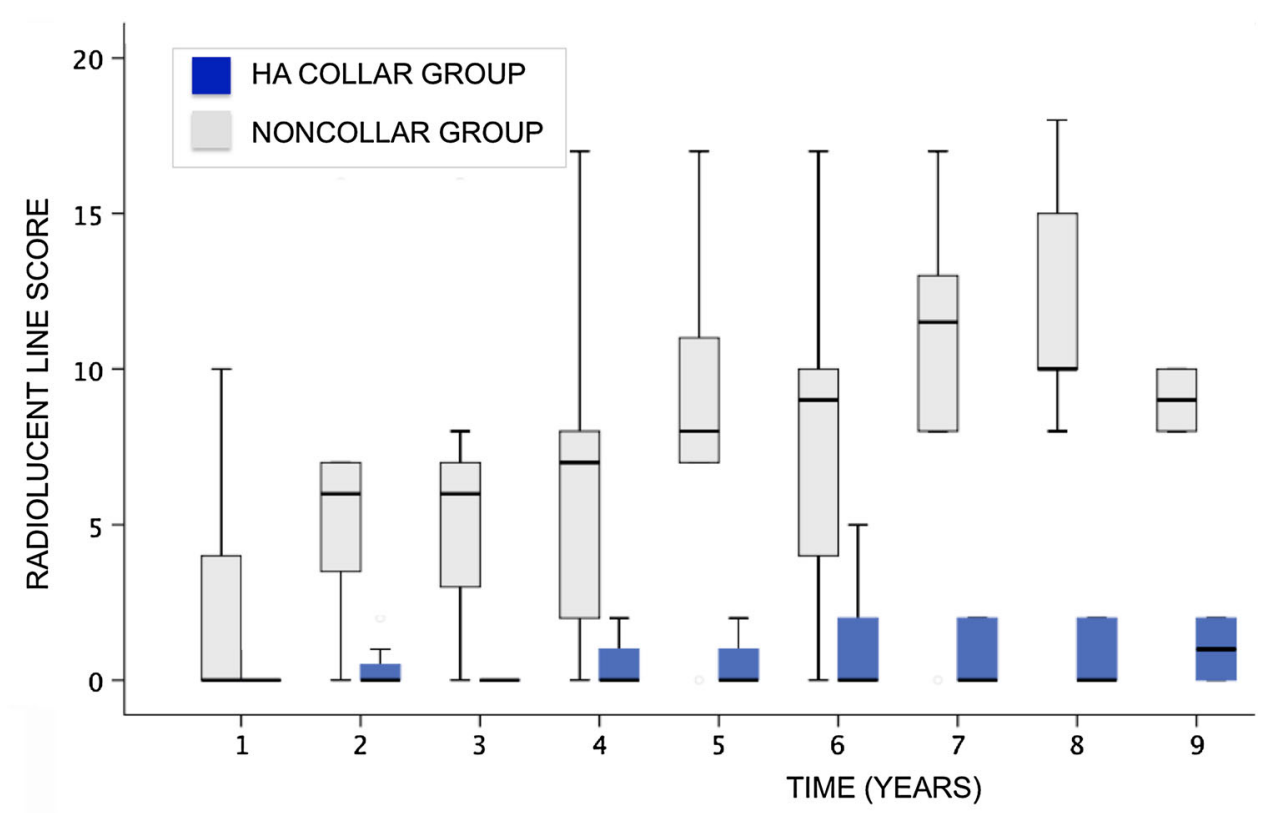

Fig. 6 The radiolucent line scores measured along the cemented stem in the HA Collar and Noncollar Groups during the study period are shown.

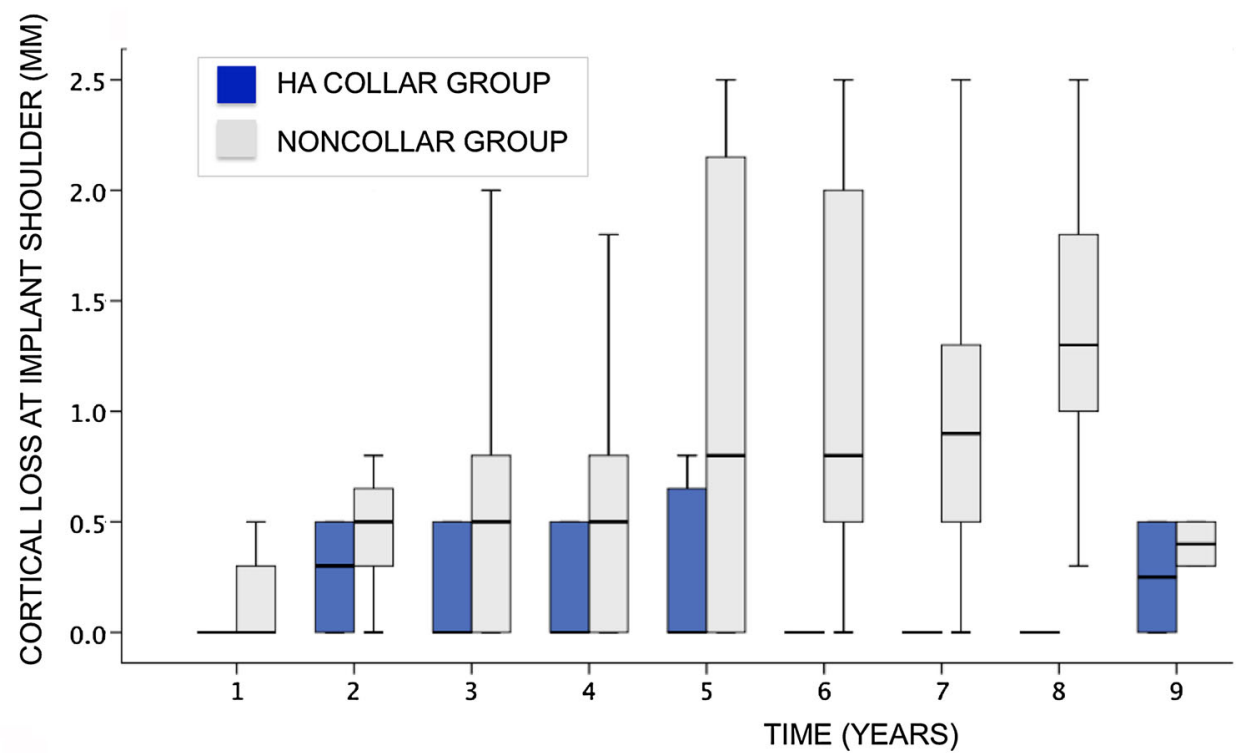

Fig. 7 The amounts of cortical bone loss measured adjacent to the implant shoulder in the HA Collar and Noncollar Groups during the study period are shown.

patients. However, patient variations in height, weight, activity level, and dose of chemotherapy were not accounted for and an additional limitation was the small sample size. Studies on massive bone tumor implants are challenging owing to the relatively low number of patients treated using a distal femoral replacement, and our study required matching patients according to age, bone resection, and followup. This substantially reduced the numbers available for analysis. In addition, the number of patients in the Noncollar Group available for pair matching was less than in the HA Collar Group, which may have introduced some error. We could not show a difference in length of followup, but the small sample size may have explained that because the HA group was a more recent cohort. Further variations were minimized because all implants were of a similar design made by one manufacturer and all surgical techniques and patient care were consistent because patients were treated at one institution. 
Although the level of osteointegration at the collar differed in the two groups, our study showed that similar and consistent amounts of extracortical bone had grown over the shoulder of both types of implants. The major difference was osteointegration of the shaft owing to use of the HA collar. Our results showed that during the mean 7-year followup period, nine of the $11 \mathrm{HA}$ collars were radiographically osteointegrated, whereas only one patient in the Noncollar Group showed contact of the bone with the implant surface. Methods to enhance osteointegration at the shoulder of massive bone tumor prostheses have been investigated and numerous different ingrowth surfaces assessed with varying amounts of extracortical growth reported [5, 14, 19, 29]. Tanzer et al. [25] reported that radiographic extracortical bone growth adjacent to porouscoated collars in 20 patients treated for bone cancer at a mean followup of 2 years did not correlate with osteointegration to the implant surface when investigated histologically. In this retrieval study no osteointegration was seen. In another study [8], results of histologic evaluation of four distal femoral replacements with a HAgrooved ingrowth collar and four implants with a smooth titanium alloy surface finish were reported. The results of that study showed that ingrowth with direct bone-implant contact was seen in all patients with a HA collar [8]. The results in that study [8] agreed with those of Tanzer et al. [25], showing no bone-implant contact in the Noncollar Group and all of the extracortical bone formed was separated from the implant surface by a relatively thick layer of fibrous tissue. In the current study, we report on osteointegration to the HA collar after radiographic analysis, and it is possible that histologic osteointegration may not have occurred in all patients despite the radiographic appearance. However, a radiolucent line between the extracortical bone and the shaft of the implant in the Noncollar Group clearly was evident in all cases except one. The importance of osteointegration at the shoulder has been recognized and some experimental studies have investigated methods to enhance extracortical bone formation, including the use of bone morphogenetic proteins [22] and stem cells [9, 18].

We found that a reduction in radiolucent line score was measured adjacent to the cemented fixation in the HA Collar Group when compared with the Noncollar group. An increase in the progression of radiolucent lines during the followup period may suggest the implant gradually is becoming aseptically loose. In our study the radiolucent line score increased with time in the Noncollar Group indicating progression toward loosening of the stem. None of the implants in the HA Collar Group had progressive radiolucent lines develop. No implants in either group were revised during the investigative period; however, results suggest that implants in all patients in the Noncollar Group gradually were becoming aseptically loose. Uncemented implants, if well osteointegrated, are thought to provide an alternative method for durable, long-term biologic fixation, where the complications of cement failure can be avoided. When compared with cemented components, lower $[4,17]$ and higher [1, 15] aseptic loosening rates have been reported. However, comparison of the two fixation types is confounded owing to differences in implant design and fixation concepts.

Our final question asked whether the presence of the HA collar may prevent cortical bone loss at the bone-shoulder implant junction. Several studies have reported that the loosening sequence in cemented massive bone tumor implants begins with osteolysis of cortical bone at the implant-bone junction [2, 3, 29, 30]. Osteolysis then slowly progresses along the bone-cement interface culminating in aseptic loosening of the implant. In our study, results showed decreased cortical loss at the shoulder of the implant in patients with HA collars.

We found that a grooved HA-coated ingrowth collar located at the shoulder of cemented distal femoral massive prostheses resulted in increased osteointegration of extracortical bone leading to a reduction in the number of progressive radiolucent lines adjacent to the intramedullary cemented stem. We also showed that the use of a HA collar led to decreased cortical bone loss adjacent to the transection site. These results suggest that the HA collar may help reduce the risk of aseptic loosening, possibly as a result of load transfer from the shoulder to the cortical bone surrounding the intramedullary stem reducing aseptic loosening. Prospective studies are needed with larger numbers of patients and longer followup to determine if our preliminary observations relate to increased longevity and reduced revision rates for loosening in implants with a HA collar.

\section{References}

1. Batta V, Coathup MJ, Parratt MT, Pollock RC, Aston WJ, Cannon SR, Skinner JA, Briggs TW, Blunn GW. Uncemented, custom-made, hydroxyapatite-coated collared distal femoral endoprostheses: up to 18 years' follow-up. J Bone Joint Surg Br. 2014;96:263-269.

2. Blunn GW, Briggs TW, Cannon SR, Walker PS, Unwin PS, Culligan S, Cobb JP. Cementless fixation for primary segmental bone tumor endoprostheses. Clin Orthop Relat Res. 2000;372:223-230.

3. Blunn GW, Wait ME. Remodelling of bone around intramedullary stems in growing patients. J Orthop Res. 1991;9:809-819.

4. Bruns J, Delling G, Gruber H, Lohmann CH, Habermann CR. Cementless fixation of megaprostheses using a conical fluted stem in the treatment of bone tumours. J Bone Joint Surg Br. 2007;89:1084-1087.

5. Chao EY, Fuchs B, Rowland CM, Ilstrup DM, Pritchard DJ, Sim FH. Long-term results of segmental prosthesis fixation by extracortical bone-bridging and ingrowth. J Bone Joint Surg Am. 2004;86:948-955. 
6. Chao EY, Sim FH. Composite fixation of segmental bone/joint defect replacement (SDR) prostheses: biological and biomechanical justifications. Chir Organi Mov. 1990;75(1 suppl):171-173.

7. Chao EY, Sim FH. Composite fixation of salvage prostheses for the hip and knee. Clin Orthop Relat Res. 1992;276:91-101.

8. Coathup MJ, Batta V, Pollock RC, Aston WJ, Cannon SR, Skinner JA, Briggs TW, Unwin PS, Blunn GW. Long-term survival of cemented distal femoral endoprostheses with a hydroxypatite-coated collar: a histological study and a radiographic follow-up. J Bone Joint Surg Am. 2013;95:1569-1575.

9. Coathup MJ, Kalia P, Konan S, Mirza K, Blunn GW. A comparison of allogeneic and autologous mesenchymal stromal cells and osteoprogenitor cells in augmenting bone formation around massive bone tumor prostheses. J Biomed Mater Res A. 2013; 101:2210-2218.

10. Farfalli GL, Boland PJ, Morris CD, Athanasian EA, Healey JH. Early equivalence of uncemented press-fit and Compress femoral fixation. Clin Orthop Relat Res. 2009;467:2792-2799.

11. Gosheger G, Gebert C, Ahrens H, Streitbuerger A, Winkelmann W, Hardes J. Endoprosthetic reconstruction in 250 patients with sarcoma. Clin Orthop Relat Res. 2006;450:164-171.

12. Griffin AM, Parsons JA, Davis AM, Bell RS, Wunder JS. Uncemented tumor endoprostheses at the knee: root causes of failure. Clin Orthop Relat Res. 2005;438:71-79.

13. Guo W, Ji T, Yang R, Tang X, Yang Y. Endoprosthetic replacement for primary tumours around the knee: experience from Peking University. J Bone Joint Surg Br. 2008;90: 1084-1089.

14. Heck DA, Chao EY, Sim FH, Pritchard DJ, Shives TC. Titanium fibermetal segmental replacement prostheses: a radiographic analysis and review of current status. Clin Orthop Relat Res. 1986;204:266-285.

15. Heisel C, Kinkel S, Bernd L, Ewerbeck V. Megaprostheses for the treatment of malignant bone tumours of the lower limbs. Int Orthop. 2006;30:452-457.

16. Jeys LM, Kulkarni A, Grimer RJ, Carter SR, Tillman RM, Abudu A. Endoprosthetic reconstruction for the treatment of musculoskeletal tumors of the appendicular skeleton and pelvis. $J$ Bone Joint Surg Am. 2008;90:1265-1271.

17. Kalia P, Blunn GW, Miller J, Bhalla A, Wiseman M, Coathup MJ. Do autologous mesenchymal stem cells augment bone growth and contact to massive bone tumour implants? Tissue Eng. 2006;12:1617-1626.

18. Kinkel S, Lehner B, Kleinhans JA, Jakubowitz E, Ewerbeck V, Heisel C. Medium to long-term results after reconstruction of bone defects at the knee with tumor endoprostheses. J Surg Oncol. 2010;101:166-169.

19. Kuo KN, Gitelis S, Sim FH, Pritchard D, Chao E, Rostoker W, Galante JO, McDonald P. Segmental replacement of long bones using titanium fiber metal composite following tumor resection. Clin Orthop Relat Res. 1983;176:108-114.

20. Mittermayer F, Krepler P, Dominkus M, Schwameis E, Sluga M, Heinzl H, Kotz R. Long-term followup of uncemented tumor endoprostheses for the lower extremity. Clin Orthop Relat Res. 2001;388:167-177.

21. Myers GJ, Abudu AT, Carter SR, Tillman RM, Grimer RJ. The long-term results of endoprosthetic replacement of the proximal tibia for bone tumours. J Bone Joint Surg Br. 2007;89:16321637.

22. Saran N, Zhang R, Turcotte RE. Osteogenic protein-1 delivered by hydroxyapatite-coated implants improves bone ingrowth in extracortical bone bridging. Clin Orthop Relat Res. 2011;469: $1470-1478$.

23. Sim FH, Chao EY. Prosthetic replacement of the knee and a large segment of the femur or tibia. J Bone Joint Surg Am. 1979;61: 887-892.

24. Simon MA, Aschliman MA, Thomas N, Mankin HJ. Limb-salvage treatment versus amputation for osteosarcoma of the distal end of the femur. J Bone Joint Surg Am. 1986;68:1331-1337.

25. Tanzer M, Turcotte R, Harvey E, Bobyn JD. Extracortical bone bridging in tumor endoprostheses: radiographic and histologic analysis. J Bone Joint Surg Am. 2003;85:2365-2370.

26. Taylor SJ, Perry JS, Meswania JM, Donaldson N, Walker PS, Cannon SR.Telemetry of forces from proximal femoral replacements and relevance to fixation. J Biomech. 1997;30:225-234.

27. Torbert JT, Fox EJ, Hosalkar HS, Ogilvie CM, Lackman RD. Endoprosthetic reconstructions: results of long-term followup of 139 patients. Clin Orthop Relat Res. 2005;438:51-59.

28. Unwin PS, Cannon SR, Grimer RJ, Kemp HB, Sneath RS, Walker PS. Aseptic loosening in cemented custom-made prosthetic replacements for bone tumours of the lower limb. $J$ Bone Joint Surg Br. 1996;78:5-13.

29. Ward WG, Johnston KS, Dorey FJ, Eckardt JJ. Extramedullary porous coating to prevent diaphyseal osteolysis and radiolucent lines around proximal tibial replacements: a preliminary report. $J$ Bone Joint Surg Am. 1993;75:976-987.

30. Ward WG, Johnston KS, Dorey FJ, Eckardt JJ. Loosening of massive proximal femoral cemented endoprostheses: radiographic evidence of loosening mechanism. J Arthroplasty. 1997;12: 741-750. 